www.jmscr.igmpublication.org

Impact Factor 5.84

Index Copernicus Value: 71.58

ISSN (e)-2347-176x ISSN (p) 2455-0450

crossref DOI: _https://dx.doi.org/10.18535/jmscr/v5i10.29

Journal Of Medical Science And Clinical Research

\title{
Incidence of the Complications of Factors Predisposing to, and the rate of Conversion of Laparoscopic Cholecystectomy to Open Cholecystectomy
}

\author{
Author \\ Dr Mohammad Eqbal Ahmad \\ MBBS MS (Surg.) FAIS, D.A. \\ Associate Professor, Dept. of Surgery, Nalanda Medical College, Patna
}

\begin{abstract}
Introduction: The first Laparoscopic cholecystectomy was performed by Erich Muhe in 1985 (Germany), followed by Mouret (1987 France) $)^{[1]}$. Laparoscopic cholecystectomy got accepted as a safe and better operation for G.B. stones in $1992^{[2]}$. Laparoscopic cholecystectomy became popular in demand with time, because of its better cosmesis, minimal incisions, low morbidity and pain, short hospital stay, and recovery ${ }^{[3]}$. But it also had it's accompanying complications ${ }^{[5,14]}$. Thus many cases of Laparoscopic cholecystectomy were converted into a Laparotomy, when any of these complications developed.

Methods: Study of the incidence of complications, predisposing factors and the rate of conversion of Laparoscopic cholecystectomy into Open Laparotomy was done. 410 patients, who were put up for Laparoscopic cholecystectomy in Nalanda Medical College, Patna from March 14 - March 17 were observed. Results: Randomized study of 410 patients of G.B. stones, put up for Laparoscopic cholecystectomy was done. Their median age was 40 yrs (range 16-64) and sex ratio was $403 \mathrm{~F}: 7 \mathrm{M}$. The common operative complications, their predisposing factors and the rate of conversion were observed.

Conclusion: 410 patients of G.B. stones, after proper clinical evaluation, Lab investigations and cardiological check-up were put up for Laparoscopic. cholecystectomy. The most common and dreadful complication was Bile Duct injury (common bile duct/common hepatic duct). It's incidence was $2.7 \%$ (11 patients) ${ }^{[11,12,13]}$. The next common complication was internal bleeding (cystric artery/liver bed / hepatic artery / aberrant vessels), seen in $1.7 \%$ (7 patients) ${ }^{[14,15]}$. Injury to intestines, liver, major vessels, due to electrocautery accidents during adhesiolysis or introduction of Veress / trocar for ports, was $0.9 \%$ (4 patients) ${ }^{[16]}$. Leakage of Bile/Spilled stones was seen in $0.7 \%$ (3 patients) ${ }^{[17]}$. Cardiac arrhythmia or hypotension due to pneumoperitoneum was seen in $0.7 \%$ (3 patients).

Keywords: Laparoscopic cholecystectomy (Lap. Chole./LC), C.B.D, Cystic artery, Hepatic artery, Murphy's Sign, Gall stones, common Hepatic D.
\end{abstract}

\section{Introduction}

Janos Veress invented the Veress needle in 1938 in Hungary to create peumothorax. Laparoscopes were gradually invented and technically improved and were initially used for gynecological operations. Muhe (1985) and Mouret 1987 did the first Laparoscopic cholecystectomy which was accepted worldwide in 1992, by the National Institutes of Health Consensus statement, as a safe surgical operation for patients of gall stones. With much smaller incisions, good cosmesis, minimal pain and morbidity, it was highly accepted ${ }^{[3]}$. Thus 
Laparoscopic cholecystectomy became very popular by demand in G.B. stones patients.

Initially Laparoscopic cholecystectomy was done by 4 ports of $10 \mathrm{~mm} 10 \mathrm{~mm} 5 \mathrm{~mm} 5 \mathrm{~mm}$. The ports became narrower to $10 \mathrm{~mm} 5 \mathrm{~mm} 2 \mathrm{~mm}$ $2 \mathrm{~mm}$, which was called Mini Laparoscopic cholecystectomy, by Norvitsky et.al ${ }^{[6]}$. These days, single port access (SPA) or single Incision Laparoscopic surgery (SILS) are being done at numerous centers ${ }^{[7]}$. Advancement of electrocautery (unipolar/bipolar), Harmonics, Ligasure, robotic surgery are making Lap. chole more and more safe.

But Laparoscopic surgery also had its own associated complications which were encountered by surgeons. Thus while operating, a Laparoscopic surgeon should be more careful in patients who have any of these, below mentioned factors ${ }^{[8,9]}$, predisposing to complications, namely

(1) Sex - Male (more common)

(2) Cholecystitis (Acute / Chronic) presenting as

i. Gangrene

ii. Pericholecystitic fluid collection

iii. G.B. Lump / Contracted G.B.

iv. Thick Walled ( $>4 \mathrm{~mm})$ G.B.

v. Murphy's sign +ve.

(3) Intra abdominal adhesions due to previous upper abdomen surgery.

(4) Infections with Neutrophilia

(5) General Diseases

i. Diabetes M. ii. Jaundice,iii. Hypoalbuminaemia.

The main complications of Laparoscopic cholecystectomy are

a. Bile Duct injury (C.B.D./ Common Hepatic Duct) : it results during adhesiolysis / dissection in Calot's triangle and in difficulty in exposing the cholecysto-cystic junction even after 30 mints ${ }^{[11,12,13]}$.

b. Internal Bleeding (Cystic Artery, Liver bed, Hepatic artery, Aberrant artery): it results during dense adhesiolysis and dissection or non-recognition of aberrant vessels ${ }^{[14,15]}$. c. Injury to intestines, liver, stomach, vessels: accidental injury by electrocautery during adhesiolysis; introduction of Veress / Trocars in patients operated earlier ${ }^{[16]}$.

d. Rare complications like Bile leakage spilled stones; pneumoperitoneum produced Arrhythmia / Hypotension were also seen.

The moment a complication is recognized, its prospects regarding correction is assessed. If negative, the operation should be converted into an Open cholecystectomy/ Laparotomy. Threshold of conversion in Laparoscopic surgery should be low, never high. Conversion should never be considered a complication or something disgraceful ${ }^{[9]}$.

\section{Patients and Methods}

In the period March'14 to March'17, 410 patients who had undergone Laparoscopic cholecystectomy after proper clinical evaluation were observed. The different intraoperative complications, factors predisposing to these complications and the rate of conversion of Laparoscopic cholecystectomy into Open cholecystectomy was studied. Laparoscopic cholecystectomy was done through 4 ports of $10 \mathrm{~mm} 10 \mathrm{~mm} 5 \mathrm{~mm} 5 \mathrm{~mm}$. The camera port was usually supraumbilical. Hasson's technique was not used. Drainage was done, when suspicion of future collection of bile/blood was there, by passing Nelaton catheter through $5 \mathrm{~mm}$ anterior axillary port.

\section{Results}

In this study of 410 patients who went for Laparoscopic. cholecystectomy, the intraoperative complications, the predisposing clinical factors and the rate of conversion of Laparoscopic cholecystectomy into Open Laparotomy was observed.

A total of 28 patients developed complications, which were managed by laparoscopic techniques and manoeuvres; or by converting the operation into Open laparotomy. Bile duct injury (C.B.D./ 
Hepatic-D.), the most common complication, was seen in $2.7 \%$ (11 patients); Internal bleeding was seen in $1.9 \%$ (7 patients); Injury to intestines, liver, major blood vessel was seen in $0.97 \%$ (4 patients); leakage of bile/spilled stones $0.7 \%$ (3 patients); Cardiac arrhythmia / Hypotension due to pneumoperitoneum was seen in $0.7 \%$ (3 patients)

Table 1: Showing the incidence of different intraoperative complications of Laparoscopic cholecystectomy, in a total of 28 patients

$\begin{array}{lcc}\begin{array}{l}\text { Complications } \\ \text { Bile Duct injury } \\ \text { (C.B.D./ Common Hepatic D.) }\end{array} & \text { No of Pts } & \text { \% Incidence } \\ \begin{array}{l}\text { Intrabdominal bleeding } \\ \text { (Cystic artery Liver bed, Hepatic artery) }\end{array} & 11 & 2.7 \% \\ \begin{array}{l}\text { Injury to Intestines/vessels } \\ \text { Bile leakage/spilled stones }\end{array} & 4 & 1.7 \% \\ \begin{array}{l}\text { Cardiac arrhythmia } \\ \text { (Pneumo peritoneum) }\end{array} & 3 & 0.97 \% \\ \end{array}$

(Pneumo peritoneum)

Amongst the associated clinical factors predisposing to the above complications, cholecystitis + pancreatitis, acute or chronic were the most common. Males had a much greater incidence of complications than females.

$\begin{array}{lcc}\begin{array}{l}\text { Complications } \\ \begin{array}{l}\text { Acute cholecystitis + Pancreatitis } \\ \text { with Pericholecystitic collection }\end{array}\end{array} & 10 & 35.7 \% \\ \begin{array}{l}\text { Chronic cholecystitis } \\ \text { (Murphy's +ve, G.B. wall >4cm) }\end{array} & 6 & 21.4 \% \\ \begin{array}{l}\text { Previous Operation upper abdomen } \\ \text { General Diseases }\end{array} & 5 & 17.8 \% \\ \begin{array}{l}\text { (D.M., Jaundice, Hypoalbuminaemia) } \\ \text { Infection (Neutrophilia) }\end{array} & 14.2 \% \\ & 3 & 10.7 \%\end{array}$

Table -3 Sex Ratio of Incidence of complications (total 28 patients having complications)

$\begin{array}{lccc}\text { Sex } & \text { No of Pts } & \text { Complication } & \% \text { Incidence } \\ \text { Male } & 7 & 2 & 28.6 \% \\ \text { Female } & 403 & 26 & 6.45 \%\end{array}$

\section{Discussion}

This study led to the observation that in patients who have Laparoscopic Cholecystectomy, incidence of developing intra-operative complications was $6.8 \%$ (28 out of 410 ). This finding was close to the figure of $1.5 \%-15 \%$ found by Sultan et.al ${ }^{[9]}$.

Bile Duct injury was found to be the most common complication, with an incidence of $1.7 \%$ (11 patients). This figure tallied with the incidence of bile duct injury of $0.3 \%-2.7 \%$ found by the
Southern Surgeon $\mathrm{Club}^{[15,16,18]}$. All of them needed conversion to Open cholecystectomy. Intraabdonominal bleeding, the next common complication, was seen with an incidence of $1.7 \%$ (7 patients). This rate was close to the mcidence of $0.3-1 \%$ found by Jatzko et. $\mathrm{Al}{ }^{[18]}$. Visualisation and haemostasis of the bleeding vessel, electrocautery by spatula in the Iiver bed, managed this complication in (1 patient). Injury to intestines, liver, vessels was seen in $0.9 \%$ (4 patients). This rate was close to the rate of $1 \%$ found Jatzko et.al ${ }^{[18]}$. Bile leakage / stone spillage was managed by suction and Nelaton catheter drainage for 3 days and thus did not need conversion.

The rate of conversion for Laparoscopic cholecystectomy into Open Laparoscopicarotomy was $5.85 \%$ (24/410). This conversion ratio was close to the rate of $5 \%-10 \%$ in the study of The Southern Surgical club, and the international conversion rate of $1.5 \%-15 \%$ (round about $5 \%$ ) $[8,9]$.

\section{Conclusion}

Bile duct Injuriy, the most common and dreadful complication of Laparoscopic cholecystectomy, may require conversion to Open Laparotomy. If needed, it should be done only by an experienced surgeon. Intra-operative bleeding can be managed by Open Laparotomy. Conversion of a Laparoscopic cholecystectomy into Open cholecystectomy / Laparotomy should not warrant any hesitation. The only question which should arise should be: When? Where? Who? ${ }^{[24]}$.

Bile duct injury can be managed by repair on a $\mathrm{T}$ tube, if the injury is minor ${ }^{[19]}$. If the injury is large, it can be managed by Endoscopic management like sphincterotomy and stenting ${ }^{[20,21]}$. Major injury of bile duct should be managed by Rouxen-Y choledocho-enterostomy ${ }^{[21,24]}$.

\section{Reference}

1. Muhe E; Laparoskopische cholecystektomie -- Endoscopic Heute; 1990 : 4 : $262-266$ 
2. National Institutes of Health (NIH) :- Gall Stones and Laparoscopic cholecystectomy; NIH Consensus Statement, Sept. 14-16, 1992

3. Shea JA, Berlin JA, Bachwich DR et.al. Indications for and outcome of cholecystectomy :- a comparison of the pre and post Laparoscopic era Ann. Surg. 1998, March, 227 (3) PP 343-350

4. Mcsherry CK :- cholecystectomy - the gold standard Arm, Surg. 1989, Sept. 158 (3), 174-178

5. Ponsky JL. Complications of laparoscopic cholecystectomy. Am. J. Surg. 161 : 393, 1991.

6. Novitsky Y.W., Kercherkw et.al :Advantage of Mini Lap. Vs conservative Lap. cholecystectomy, Arch.Surg. 2005 Dec., 140 (12). 1178-1183

7. Yamazaki M, Yasuda H, Koda K, : Single incision Lap. cholecystectomy - a systemic review of methodology and outcomes, Surg. Today May, 222014

8. Hunter JG : - Acute cholecystitis revisited - get it while it's hot, Ann. Surg. 1998, April, 227 (4), 468-469

9. Sultan AM, EL Nakeeb A, et.al :- risk factors for conversion during Lap. Chole Analysis of ten years experience at Single Tertiary referral center, Dig. Surg, 2013, April :26 : 30(1). 51 - 55

10. Bhansali SK. Preoperative complications of gall stones and their relevance to treatment and prognosis-experience with 451 cases. Am J Gastroenterol 80: 648, 1985.

11. Martin RF, Rossi RL, Bile duct injuries :spectrum of mechanisms of injury and their prevention; Surg. Clin. North Am. 4 : $781 ; 1994$

12. Steward L, Way LW:- Bile duct injuries during laparoscopic cholecystectomyfactors that influence the result of treatment. Arch Surg. 130: 1123, 1995.
13. Schol EPG, Go P.M. et.al. : - Risk factors for bile duct injury in Lap.chole- analysis of 49 cases; Br. J. Surg; 1994 : 81 : 17861788

14. Downs SH, Ryoston CMS, Black NA et.al. Systematic review of the effectiveness and safety of laparoscopic cholecystectomy. Ann Roy Coll Surg. Engl. 78 : 241, 1996

15. Moore M.J. Bennett OL : - The learing curve for Lap. Chole. The Southern Surgeons Club, Am.J. Surg. 1995: July; 170(1), 55-59

16. The Southern Surgeons Club : - A prospective analysis of 1518 Lap. Cholecystectomies, N.Eng. J. Med. 1991 April 18 : 324 (16): 1073 - 1078

17. Huang S.M. Wu. C.W. et.al:- Bile Duct injury and bile leakage in Lap.Chole; Br. J. Surg. $1995: 80: 1590-1592$

18. Jatzko G. et.al. :- Multivariate comparison of complications after Lap.Chole. and Open Chole; Arm. Surg; 1995 : 221 : 381386

19. Fabre J.M., Fagot H., et.al. : - Lap. chole. in complicated cholelithiasis Surg. Endosc; $1994: 8: 1198-1201$

20. Bedogni G. Mortilla M.G. et.al. : - 1994. The role of endoscopic treatment of early biliary complication of Lap. chole./Lap. Surg. pp. 145-188

21. Goldman, Lee (2011) :- Goldman's Cecil Medicine 24thed., Philadelphia Elsevier Saunders, p 940, p 1017.

22. Glasgow RE, Mulvihill SJ (2010) :Treatment of Gall Stones disease in M, Fieldman et.al; ed: Gastro-inestinal and liver diseases, $9^{\text {th }}$ ed vol-I pp 1121-1138 Philadelphia Saunders.

23. Joseph M (2012) - Single incision Lap.chole. associated with increased rati of Bile duct Injury, Ann. Surg. 206(I) p-1-6.

24. Kapoor V.K. (2009) :- Bile duct Injury repair - When, where who in journal Hepato-Biliary pancreatic surgery, 14(5) pp 476-479. 